\title{
Cyprus: The Submerged Final Palaeolithic of Aspros Dive Site C
}

Albert J. Ammerman

\section{Abstract}

Underwater reconnaissance work in front of the early site of Aspros on the west coast of Cyprus has led to the recovery of lithic artefacts that date to the Final Palaeolithic. Survey work on Cyprus was initially focused on the search for pre-Neolithic archaeology on land, resulting in the discovery of sites on formations of aeolianite along the modern coastline. Given their inferred pre-Neolithic age at a time when sea levels were significantly lower than present, their geomorphological setting was used to predict targets for underwater survey offshore, resulting in the discovery of Dive Site C. In the eastern Mediterranean, no other site of this age has been found in a submerged context so far. At the end of the Pleistocene, this place stood at the foot of an aeolianite cliff that once formed part of the north bank of the Aspros River. Detailed analysis of the lithics at Dive Site C has identified diagnostic chipped stone tools in a hypermicrolithic tradition. This chapter sets out the steps that led to the underwater discovery, describes the lithic industries, presents the resulting gains in new knowledge and highlights the contribution that underwater archaeology is making to a better understanding of

A. J. Ammerman $(\triangle)$

Department of the Classics, Colgate University, Hamilton, NY, USA

e-mail: aammerman@colgate.edu the Epipalaeolithic on Cyprus. Of particular interest are the close parallels between the reduction technology and the stone tool types at Aspros Dive Cite $\mathrm{C}$ and those from the levels of the Öküzini Cave in southern Turkey, which date to the time of the Younger Dryas.

\section{Keywords}

Underwater archaeology $\cdot$ Cyprus $\cdot$ Final Palaeolithic $\cdot$ Aspros $\cdot$ Voyaging $\cdot$ Younger Dryas

\subsection{Introduction}

One of the challenges in the study of voyaging foragers in the Mediterranean is that sea levels were appreciably lower in the time before the Neolithic period. In the case of the site of Aspros on land (Figs. 22.1, and 22.2), which dates to the Late Palaeolithic or the Epipalaeolithic as it is called locally on Cyprus and in the Levant (Ammerman 2013, 2014a; Kaczanowska et al. 2014; see also Knapp 2013), the distance from the shoreline today to the one 12,000 years ago was around $1.4 \mathrm{~km}$ (Fig. 22.3). In turn this raises the question of whether what one finds when one does a survey on land provides a good guide to what was happening on the coastline at the end of the Pleistocene. This has been an open question for some time. One way to address this is by con- 


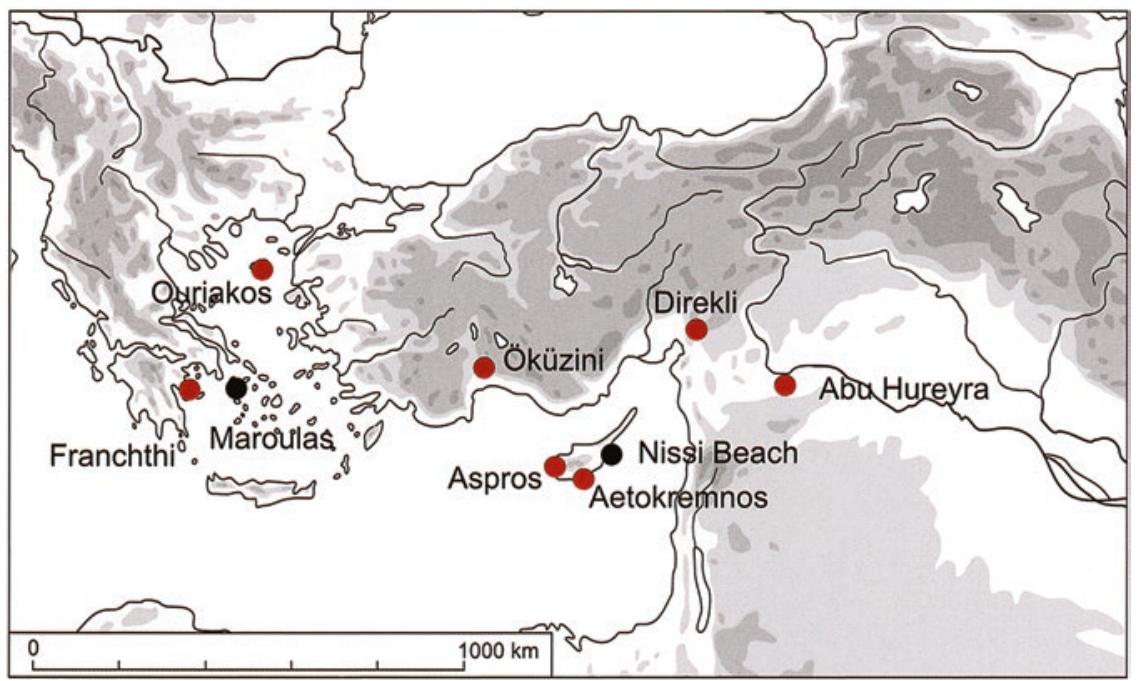

Fig. 22.1 Map showing the location of seven sites that date to the time of the Younger Dryas (c. 10,8009500 cal BC) in the eastern Mediterranean: Abu Hureyra, Aetokremnos, Aspros, Direkli Cave, Öküzini Cave, Ouriakos and Franchthi (red dots). Black dots give the location of two sites that date to the first half of the ninth millennium cal BC: Nissi Beach and Maroulas

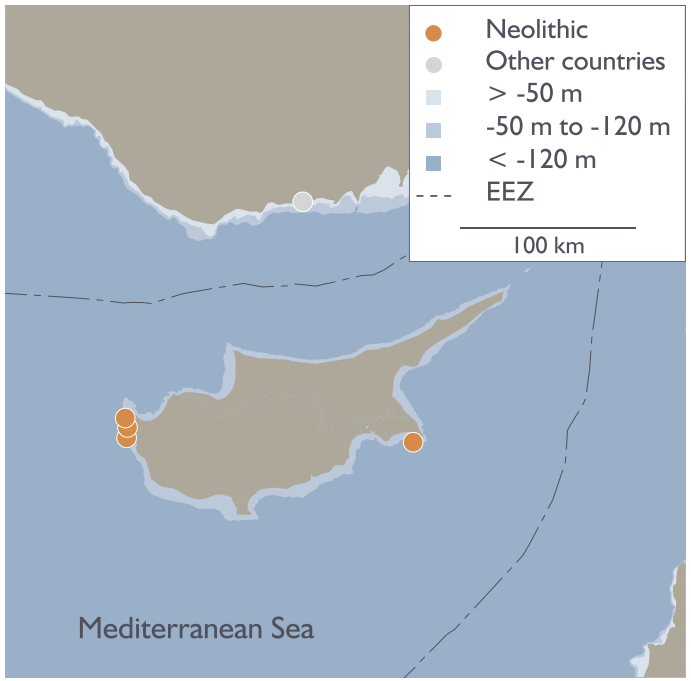

Fig. 22.2 Location of underwater sites on Cyprus. Sites in the west are at Aspros, the site in the east is Nissi Beach. Site information from the SPLASHCOS Viewer http:// splashcos-viewer.eu. Drawing by Moritz Mennenga

ducting reconnaissance work on the seafloor. While a good case can be made in the context of method and theory in archaeology for engaging with submerged prehistory (e.g., Bailey 2013 and references therein), archaeologists on Cyprus have been hesitant to attempt this kind of work. There were practical considerations that kept them from getting their feet wet. To begin with, it takes time, effort and money to put together the team and equipment to do underwater archaeology. Moreover, the sizes of the lithics that one is attempting to find are quite small, the pieces of chipped stone are often less than $1 \mathrm{~cm}$ in length, and their visibility on the seafloor is even lower than it is on land. For many years it was hard enough for archaeologists working on land to find pre-Neolithic sites on the islands in the eastern Mediterranean (Ammerman 2010). Given the risks involved - the chances of returning home empty-handed-it was understandable that archaeologists on Cyprus held back from taking the plunge. Dive Site C was discovered in July 2007 on the west coast of Cyprus at a depth of $12 \mathrm{~m}$ in the water, at a place that once stood on the north bank of the Aspros River when sea level was lower than today (Ammerman et al. 2008, 2011).

It is worth underscoring two things by way of introduction. First, what was undertaken at Dive Site $\mathrm{C}$ was not a routine piece of work in the field. None of us had ever worked at a Palaeolithic site 


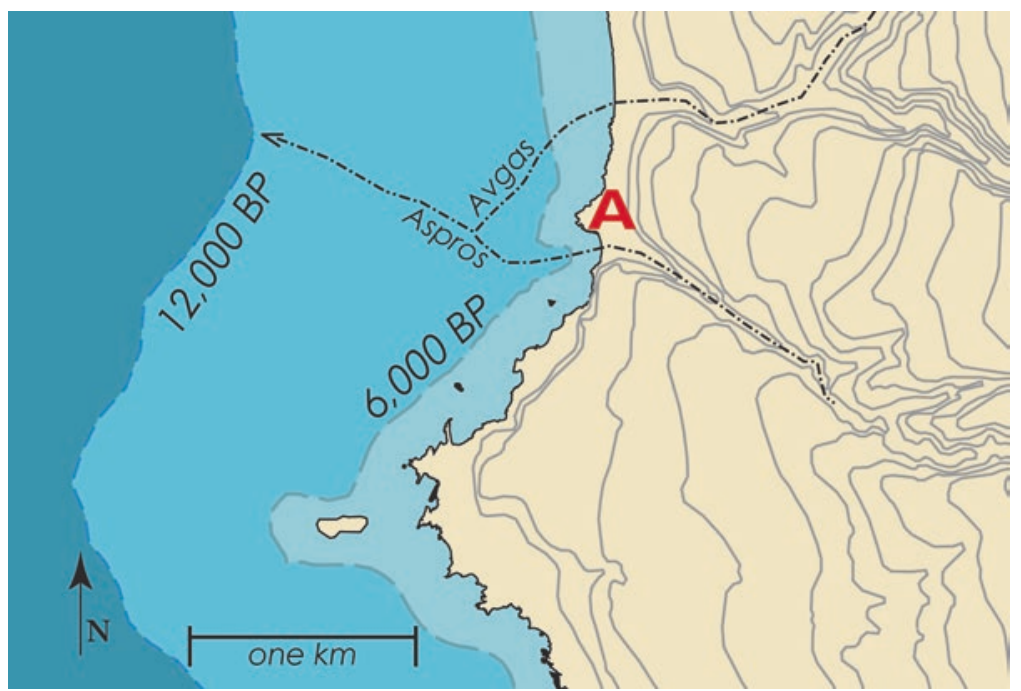

Fig. 22.3 Map showing the site of Aspros on land (A), located above the confluence of the Avgas and Aspros Rivers, with their approximate courses to three shorelines: (1) c. 12,000 years BP (10,000 cal BC) at c.70 m below sea level today; (2) c. $6000 \mathrm{BP}$ (c. $4000 \mathrm{cal} \mathrm{BC}$ ) at c. $8 \mathrm{~m}$ below sea level today, dashed line; and (3) the present day, $0 \mathrm{~m}$, solid line. For land above sea level today, the contour lines are at $20 \mathrm{~m}$ intervals

in a submerged context before, and underwater archaeology was not part of my own training. In retrospect, one can see it as the logical thing to do. Perhaps 'pioneering venture' is the best term to use in describing what we were setting out to do. Second, we had great good fortune to find Dive Site C, given the limited time and resources that were available to us. In addition, doing underwater archaeology in a hot summer month led fortuitously to the important discovery of sea salt in shallow basins in the aeolianite bedrock on the coast (Fig. 22.4; Ammerman et al. 2008, Fig. 10; Ammerman 2014a, Fig. 19). As an annually renewing resource that occurs right on the shoreline, salt might be a good reason for foragers based on the mainland to voyage out to Cyprus in the summer months.

On the other hand, we failed to appreciate the full significance of the lithic finds in our two preliminary reports (Ammerman et al. 2008, p 19; Ammerman et al. 2011, p 266-267), and it was only when Janusz Kozlowski and Malgorzata Kaczanowska, leading lithic specialists from Poland, agreed to step in and re-examine all of the lithics found at the sites of Aspros and Nissi
Beach including the material from Dive Site C that we were able to appreciate their full significance (Kaczanowska and Kozlowski 2014a), in particular the close parallels between the chipped stone tools and reduction technology at Dive Site $\mathrm{C}$ and those found in the upper levels at the Öküzini Cave in southern Turkey (Yalçinkaya et al. 2002).

This chapter outlines the steps that led to underwater work at Aspros in 2007, sets out the predictive strategy used to locate underwater sites, and summarizes the results of underwater reconnaissance with particular attention to the analysis of the lithics at Aspros Dive Sie C (for further detail see Ammerman 2013, 2014a).

\subsection{Steps in the Fieldwork on Land}

When I first went out to Cyprus in 2003 to find the missing pre-Neolithic sites on the island, the notion of doing underwater archaeology was the last thing that I had in mind. As late as 2003, there was only one reliable pre-Neolithic site on 


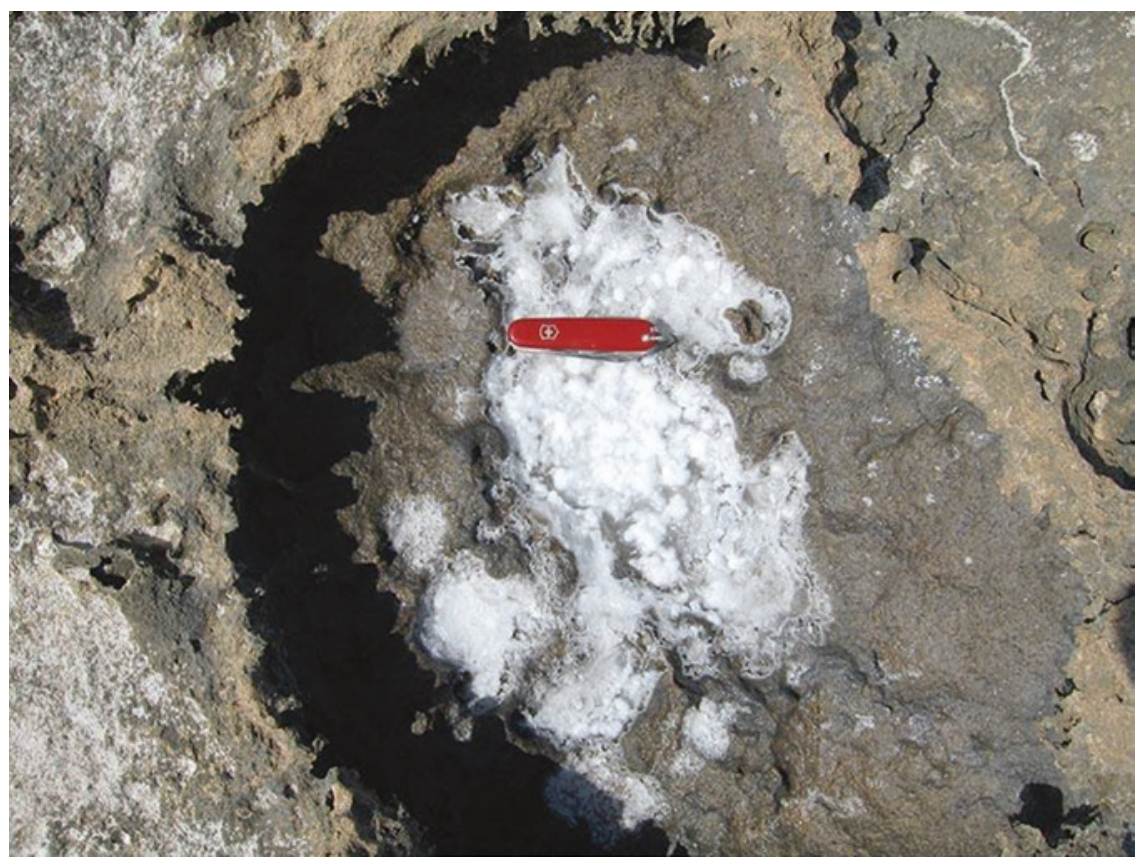

Fig. 22.4 Sea salt on the shoreline at Aspros. The salt forms when spray from the sea collects in shallow depressions in the aeolianite rock and the water dries out in the sun during the summer months. The sea salt there was a resource that renewed itself each year. Photo by Albert Ammerman

the island of Cyprus, the much-debated rock shelter known as Aetokremnos on the Akrotiri Peninsula (Simmons 1999; Ammermans and Noller 2005; Zazzo et al. 2015). Even as late as 2007, there was in the literature no site of Mesolithic or Palaeolithic age that was known on the island of Crete. In short, the whole question of early voyaging to offshore islands in the Mediterranean Sea-Cyprus, Crete, Corsica, Sardinia and the Balearic Islands-was still up in the air at the time.

On Cyprus we took a new approach-one that focused on the location of sites on or near the coast and the visibility of early sites on the modern land surface (Ammerman et al. 2006). We soon found Nissi Beach at Agia Napa in January of 2004 and then Aspros in the Akamas in December of the same year (Fig. 22.1;
Ammerman 2010). By the end of 2005, the reconnaissance work on land had led to the discovery of ten sites on formations of aeolianite on the coasts of Cyprus, all of them with pebbleand-flake-based lithic reduction technologies quite different from the blade-oriented traditions found at Neolithic sites on the island and therefore inferred to be pre-Neolithic in date. This challenged conventional wisdom at the time, namely, that hunter-gatherers were reluctant seafarers in the Mediterranean and that pre-Neolithic sites were difficult to find on its islands (Cherry 1990). We now had good evidence for crossing the sea to the offshore island of Cyprus in the time before the Neolithic period. In light of the heightened mobility of Natufian hunterforagers in the Levant during the late Epipalaeolithic (Bar-Yosef 1998; Boyd 2006), 
one could also put forward the working hypothesis that, in response to the cold snap of the Younger Dryas (dated to the period 12,80011,500 cal BP), voyaging to Cyprus now made it possible for populations in the Levant to cope with a climatic downturn by enlarging even further their territorial range (Broodbank 2006; Ammerman 2010).

The next step in the fieldwork was to place the early sites at Aspros and Nissi Beach into their environmental context. Jay Noller, a soil scientist and coastal geologist, took the lead in this line of investigation. He studied first the aeolianite rock (old lithified sand dunes) and then examined the thin palaeosols that had formed on top of this bedrock during the closing years of the Pleistocene. The palaeosols at both sites were found to have very low productivity in ecological terms. In short, the soils are of little or no use for purposes of agriculture either today or in prehistoric times. Noller also mapped the geomorphology of the area in the vicinity of Aspros. Of particular interest for our present purposes, he also produced a map that shows the confluence of the Avgas and Aspros Rivers with the approximate positions of the shorelines at 6000 and 12,000 years ago (Fig. 22.3; Ammerman et al. 2007, Fig. 3). In the case of the earlier shoreline, it was taken to stand at c. $70 \mathrm{~m}$ below modern sea level. This reconstruction stands up quite well today in the context of the slightly lower value for sea level at the end of the Younger Dryas (c. $60 \mathrm{~m}$ ) recently proposed by Lambeck and coworkers (Lambeck et al. 2014). The distance from the west side of the site of Aspros on land to the shoreline at c. 10,000 cal BC is just over $1.4 \mathrm{~km}$.

The third step was to excavate six small trial trenches at Aspros in 2007 and 2008 (for their locations, see Ammerman et al. 2008, Fig. 4). While the excavations of the palaeosols did yield a certain number of lithics in each case (ones similar to those on the site's surface), none of the trenches produced a good feature or concentra- tion of lithics. The counts of the lithics recovered from each of the first four trenches are given in our third report on early sites on Cyprus (Ammerman et al. 2008, Table 4). In turn this now led to the realization that the trial trenches were all made in a place that was too far from the coast at the time of interest. If we wished to work at sites closer to the shoreline in late Palaeolithic times, we would have to look for them offshore and under water (Ammerman et al. 2011, p 269).

\subsection{Underwater Reconnaissance Work at Dive Site C}

Alan Blum, a geologist at Cornell University, first drew my attention to the effect of "case hardening' of the aeolianite bedrock that occurs on the north side of the Aspros River. As shown in Fig. 22.5, the aeolianite has a hard, upper carapace, but it is easy for the lower part of the cliff to become undercut when it is exposed to the elements over time, due to a lesser degree of lithification with depth in this rock. Shallow rock shelters can even form in some places along this cliff, which is $4-5 \mathrm{~m}$ high. In addition, the case hardening of the aeolianite in the valley, as mentioned before, creates a more resistant place on the coast, one that has a much better chance of surviving a marine transgression. Accordingly, we chose to focus our underwater searches on the submerged north bank of the palaeochannel, and this was the key decision behind the success of the work at Dive Site C.

Dive Site C is located some $130 \mathrm{~m}$ from the present-day coastline (Fig. 22.6). The foot of the aeolianite cliff on the river's north bank stands at about $12 \mathrm{~m}$ below sea level today, and the top of the cliff stands some $4 \mathrm{~m}$ above the foot of this cliff. Six dives were made in this place during the field season. On the whole, visibility was more limited in the upper part of Dive Site C (the flat area at the top of the cliff). For this reason, less effort was put into coverage of the seabed there. 


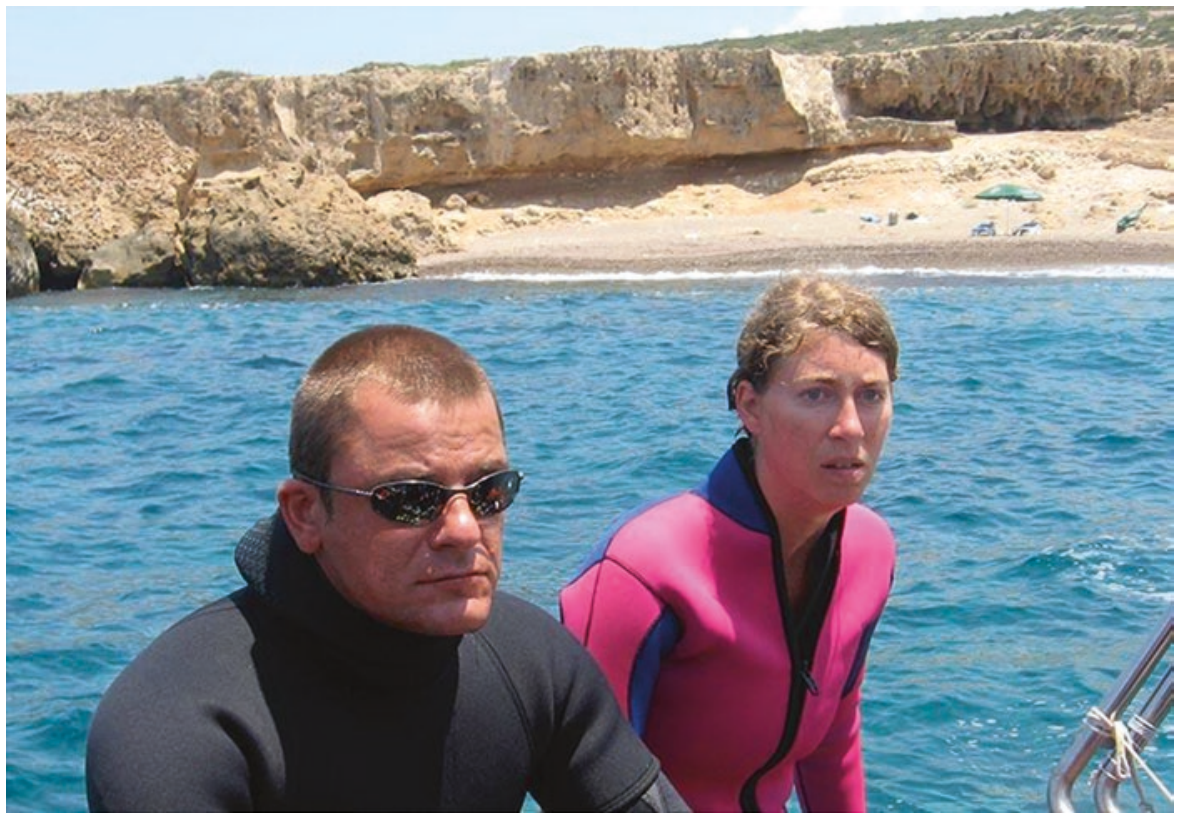

Fig. 22.5 View of the aeolianite cliff on the south side of the site of Aspros on land with members of the dive team in the foreground. Note the collapse of the overhanging upper part of the aeolianite cliff on the left. No archaeology is observed in the rock shelter to the right since local shepherds have removed all the deposits down to the bedrock over the centuries. Photo by Albert Ammerman

The dives were made using standard SCUBA equipment, and each one lasted for less than an hour. Once a good potential place such as Dive Site $\mathrm{C}$ was identified by means of wider coverage, two or three divers working together as a 'lithic recovery' team were then assigned to cover it more intensively (Figs. 22.7, and 22.8), while a supervisor kept an eye on the work in progress and recorded the area. Professional underwater cinematography was also used to document each dive site. Those working on a lithic recovery team were asked to collect everything they encountered, including pieces of very small size, and not to be selective in what they picked up. Later, the materials would be sorted and studied. During a given dive, each person collected his or her own pieces and put them in a separate labelled bag. In terms of methodology, it was of interest to see whether or not there were patterns of difference in recovery from one diver to the next. This turned out to be the case: two of the divers were consistently better at finding the smaller pieces.

\subsection{The Study of the Lithics}

Only 38 lithic artefacts were identified in the original study of the material from Dive Site C, but the later analysis by Kaczanowska and Kozlowski (2014a) identified a total of 60 lithic artefacts from the same set of material. This came as a complete surprise to us. We were expecting to see some degree of difference to emerge from the re-examination of the material but not such a big one. Kaczanowska and Kozlowski were now able to identify 17 retouched tools, 1 core, 2 core fragments and 4 blade fragments (see Figs. 22.9, and 22.10; Table 22.1). Even for them the study of the lithics at Dive Site C was far from easy given the microlithic character of the material. They also analyzed all the lithic materials recov- 


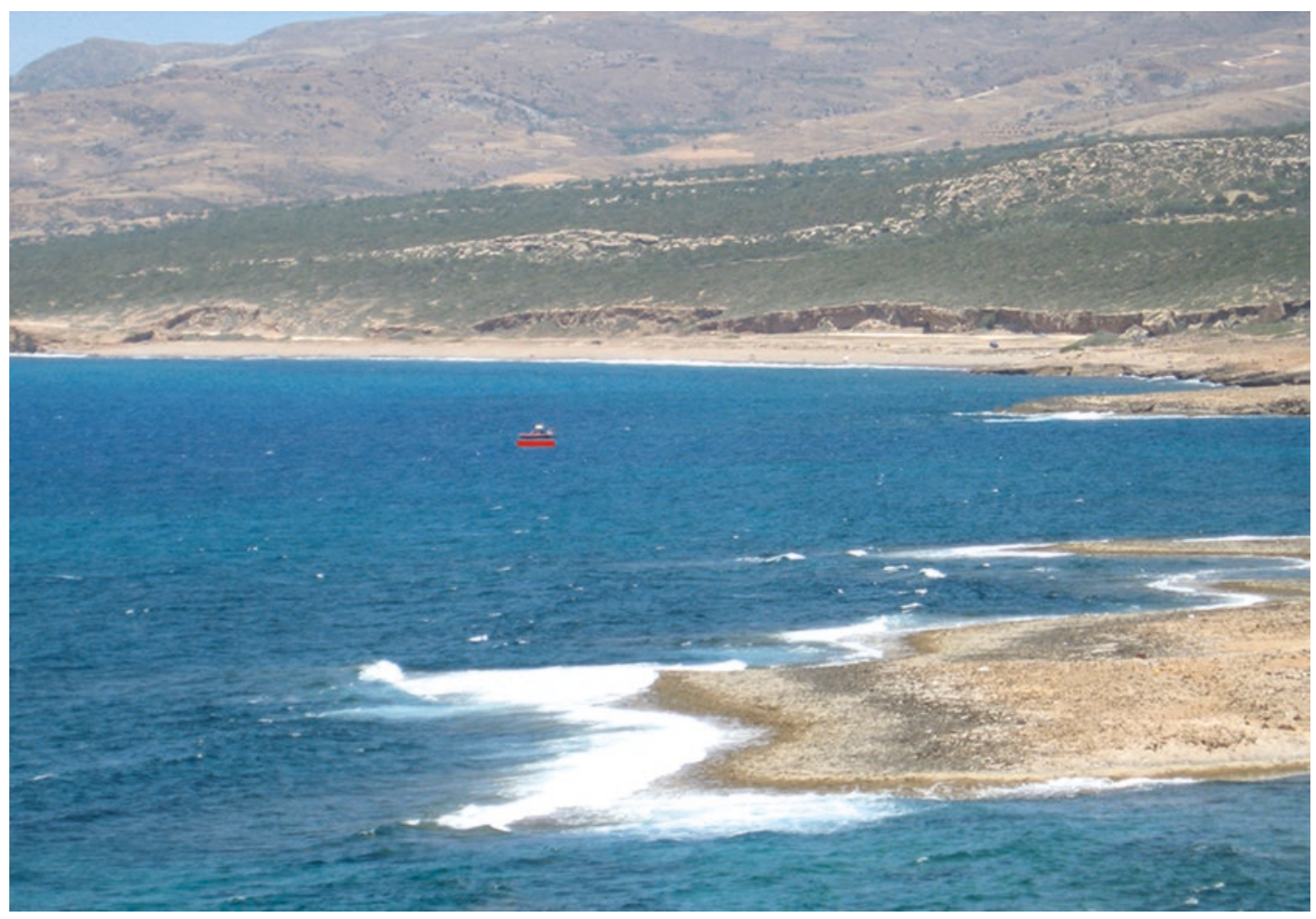

Fig. 22.6 View from the south showing the location of Dive Site C and the landscape of the Akamas to the north. The RIB boat is underlined in red and the site of Aspros on land is just visible on the far right. Photo by Albert Ammerman

ered at the site of Aspros on land (Kaczanowska et al. 2014) as well as those found on land at the site of Nissi Beach (Kaczanowska and Kozlowski 2014b).

One of the striking features of the raw material used for making the lithics at Dive Site $\mathrm{C}$ is their diversity. Three basic classes of raw materials are observed: flints and cherts, radiolarites, and coarse-grained quartzite. Macroscopically the flints comprise the most diverse group, dividing into 13 variants on the basis of colour, translucency and inclusions. In all there are 16 different raw materials that were recognized by Kaczanowska and Kozlowski (2014a; see also the last column in Table 22.1). There are two main inferences to draw from this. First, it is fair to say that the hunter-gatherers were not all that selective in the pebbles they chose to work. Second, what one appears to be dealing with at
Dive Site $\mathrm{C}$ are people who were on the move and who went to sea from time to time as part of their mobile way of life.

For the lithics recovered on land at Aspros, Kozlowski believes that all of the chipped stone there (more than 1700 pieces) dates to the time of the Epipalaeolithic. He finds no evidence for cores or stone tool types associated with either the PPNA or the PPNB on Cyprus. This holds for Dive Site $\mathrm{C}$ as well. This result makes good sense since most of the landscape at Aspros consists of formations of aeolianite, which were poor for early forms of agro-pastoralism. On the other hand, there are clear differences between the lithics found at Aspros (on land) and those recovered at Dive Site C. In short, the lithic tradition at the latter can be described as a hypermicrolithic one. The chipped stone pieces there are consistently of small size, including the core 


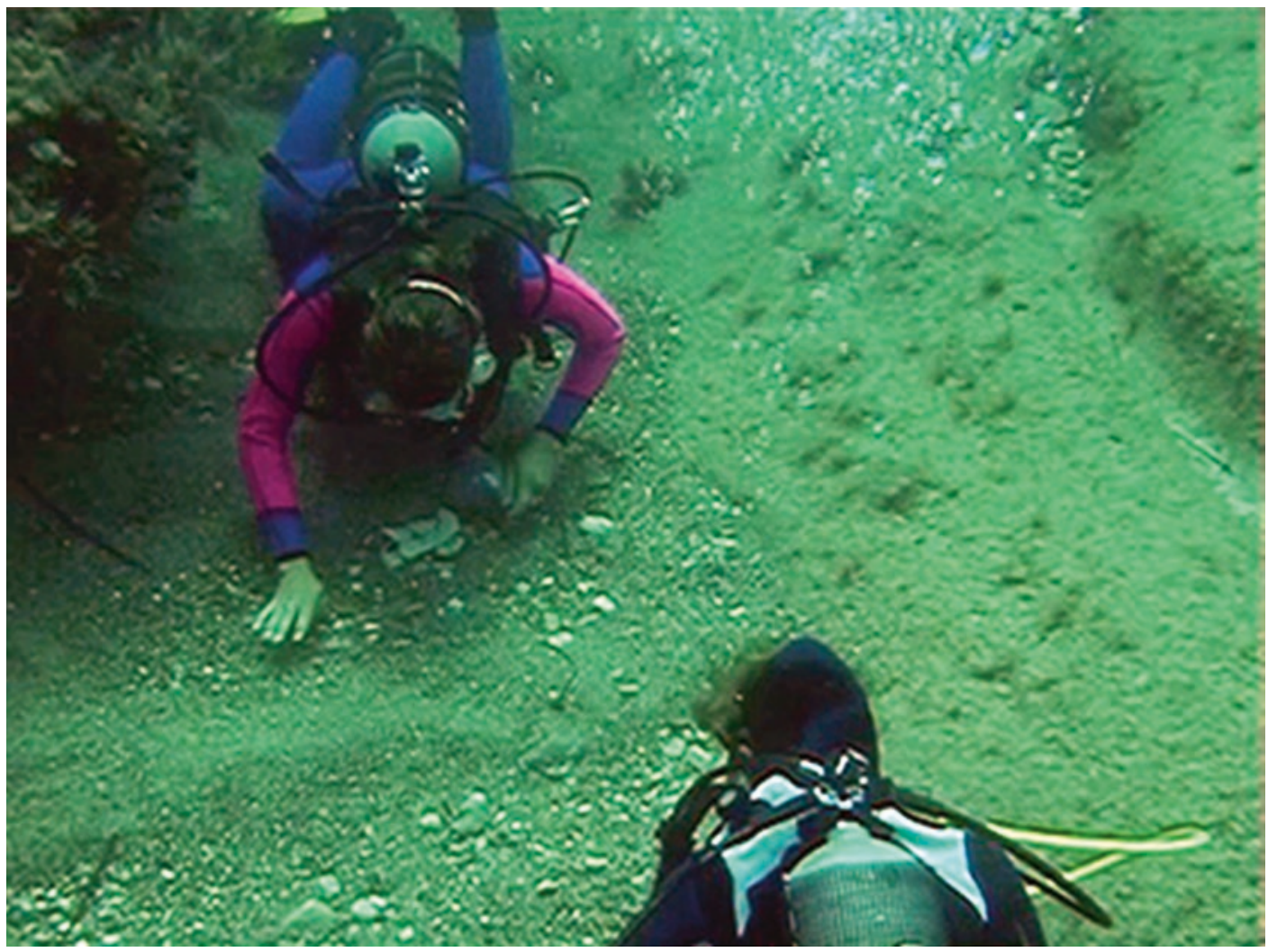

Fig. 22.7 Work in progress at Dive Site C: note the base of the cliff on the left of the diver on the left side of the photograph. Photo by Albert Ammerman

and two core fragments (Fig. 22.9:1-3), and there is a much higher proportion of backed pieces and segments (Fig. 22.10: 1-5). There are interestingly close parallels between the chipped stone tools at Dive Site C and those found in the upper levels of the Ökuzini Cave in Turkey (Kaczanowska and Kozlowski 2014a, p 63). Here it is worth adding that the upper level at Öküzini has been radiocarbon dated to the time of the Younger Dryas (Yalçinkaya et al. 2002). This is why the lithics at Dive Site C can be firmly attributed to the Final Palaeolithic. At the same time, what is found at Dive Site C now offers a new face of the Epipalaeolithic on Cyprus - the assemblages of this age that occur at other early sites on the island all have a more generic character and lack close parallels with lithic traditions on the mainland.

\subsection{Discussion}

At all the pre-Neolithic sites found on formations of aeolianite on Cyprus, one finds much the same pebble-and-flake-based tradition of lithic reduction technology. While it was definitely rewarding to find the missing pre-Neolithic sites on the island, we initially tended to discount what appeared to be a rough and expedient way of making chipped stone tools. Most of the archaeologists working on our project came from a background in Neolithic studies, 


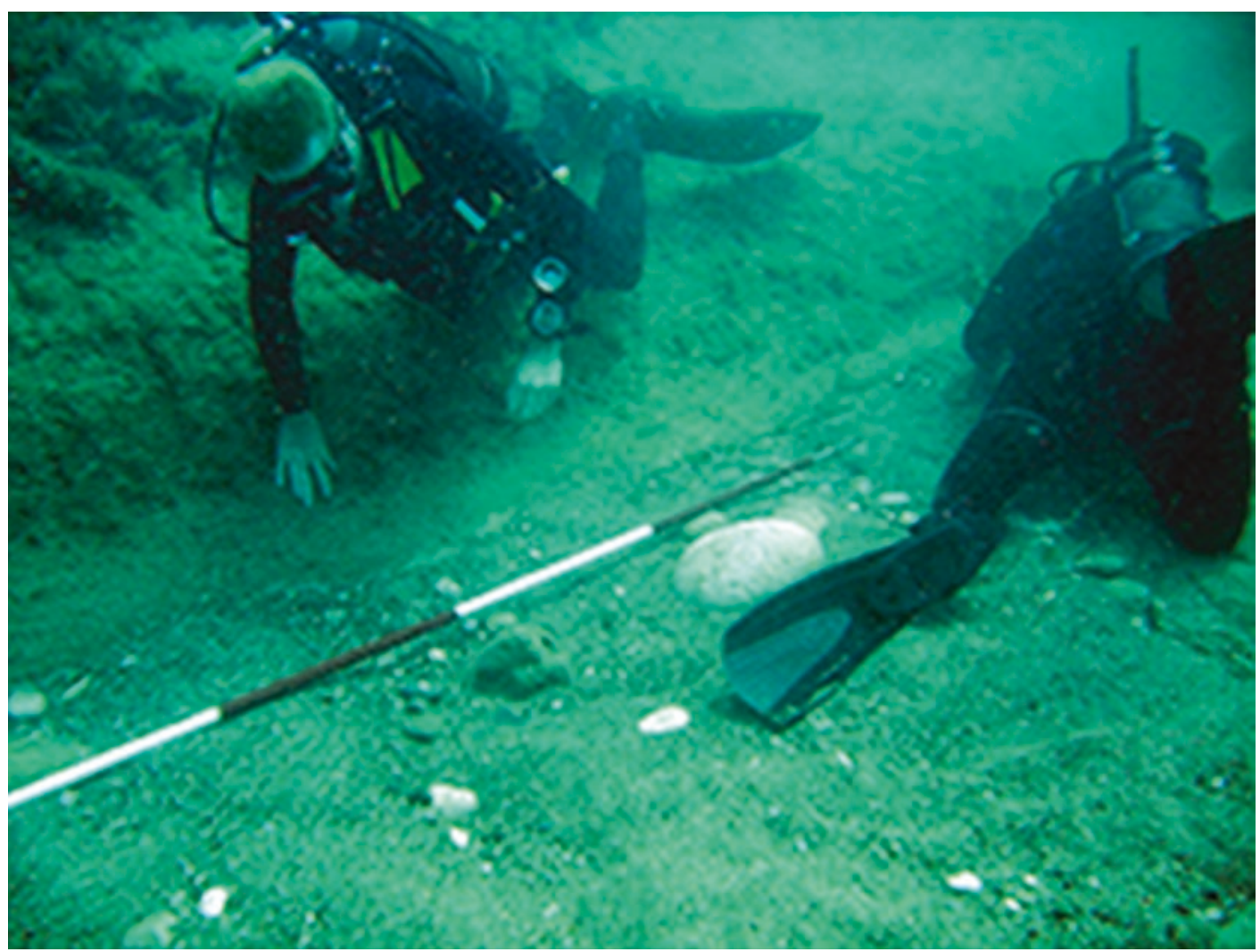

Fig. 22.8 Work in progress at Dive Site C: note that the diver on the left is using a slow hand-waving technique to increase the visibility of small chipped stone tools. Photo by Albert Ammerman

where the lithic traditions are commonly oriented toward the production of blades and not flakes. It took us a number of years to get over this bias and see the lithics at Aspros (through the eyes of Kozlowski) in a more positive light. Thus, far from this being a makeshift and expedient lithic technology, it is better described as a sophisticated and demanding one. For instance, the small segments are quite difficult to make. This reduction technology in combination with the use of the wide range of raw materials observed at Dive Site C makes good sense for mobile hunter-gatherers. For voyaging foragers on the move, this meant that they did not have to stop and search for an outcrop of flint or chert. Instead it was easier to look on the beach or in shallow water for suitable pebbles that were more immediately at hand. Here it is of interest to recall the standardized, or the so-called simple, lithic tradition that was widely used by early voyaging foragers in the case of Australia (Balme and O'Connor 2014). Finally, the best way to reach the island of Cyprus by means of a small boat or watercraft in the summer months (when sea salt could be collected on the shoreline) was by voyaging from the west (Bar-Yosef Mayer et al. 2015), that is, from the south coast of Turkey where the Öküzini Cave is located.

In closing, it is worth remembering that many prehistoric archaeologists who work on Cyprus had serious doubts that anything of interest would come out of the underwater reconnaissance work 

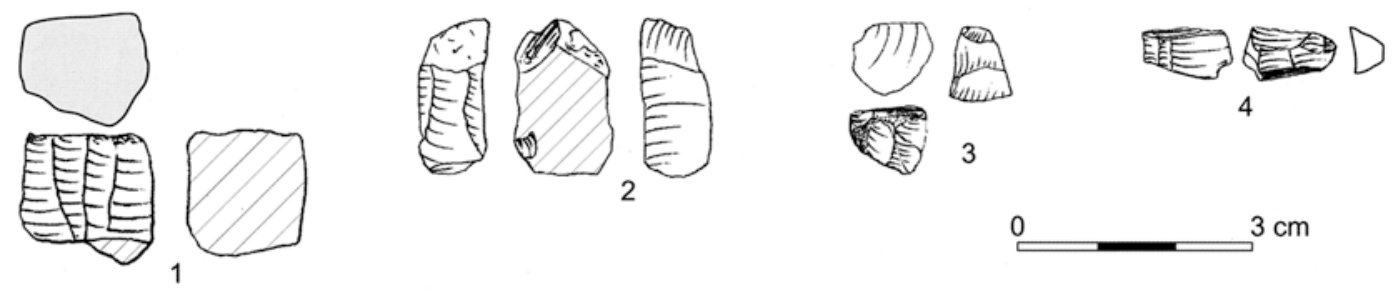
$3 \mathrm{~cm}$
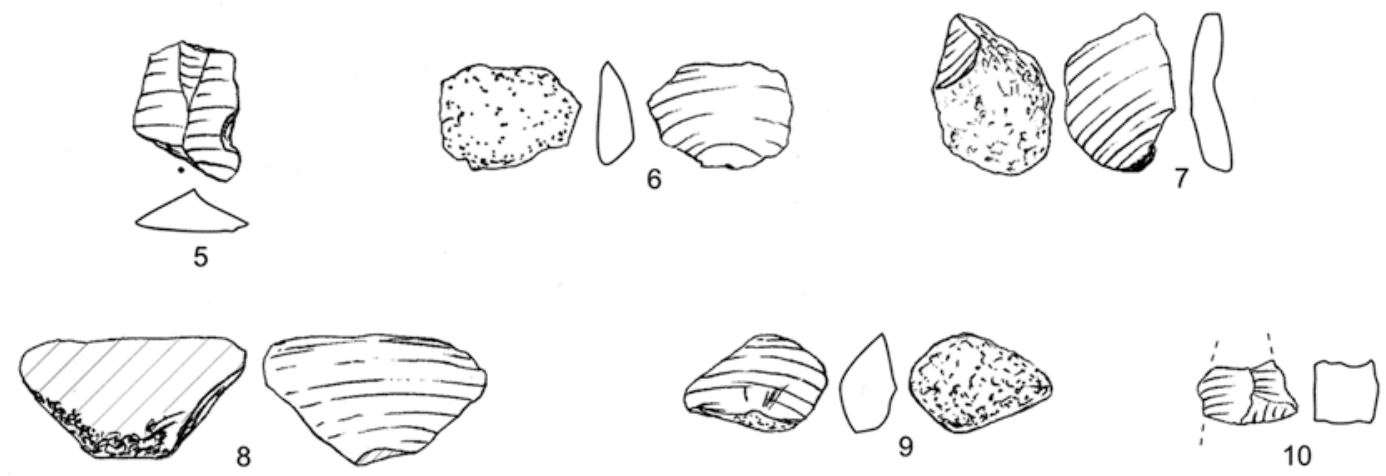

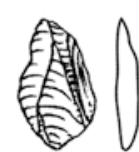

11

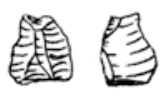

12

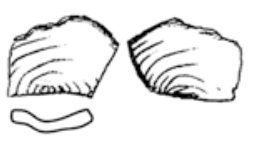

13

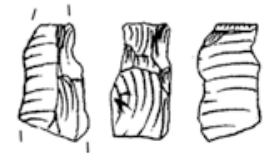

14

Fig. 22.9 Drawings of the chipped stone artefacts recovered from Dive Site C at Aspros. From Kaczanowska and Kozlowski (2014a: Plate 1). See Table 22.1 for the description of the respective pieces. Drawings by Janusz Kozłowski

that we were planning to do in front of Aspros in 2007. This was fully understandable since we were trying to do something new on the island. In fact, there was the risk that our pioneering venture would fail. Now we know that it is not only possible to do this kind of work on Cyprus but that it can be organized by an archaeologist who had almost no previous experience in the field of underwater archaeology.

The existence of submerged sites of late Palaeolithic age on Cyprus is no longer just an idea. It is a reality. In turn this now changes our perspective on where and on how we should conduct fieldwork in research on voyaging forag- ers in the eastern Mediterranean (Ammerman 2014b).

We are, of course, just at the very beginning of research on submerged prehistoric sites on Cyprus. If we now look forward to what needs to be done next at Dive Site C, it is useful to consider three lines of work. First, there is the need to return to the site and enlarge in spatial terms the collection of lithics at the foot of the cliff and also in the area at the top of it where four pieces were recovered in 2007 (see the last column in Table 22.1). Here it would be helpful to bring out to Cyprus mechanical sieving equipment of the kind used in Denmark for this 

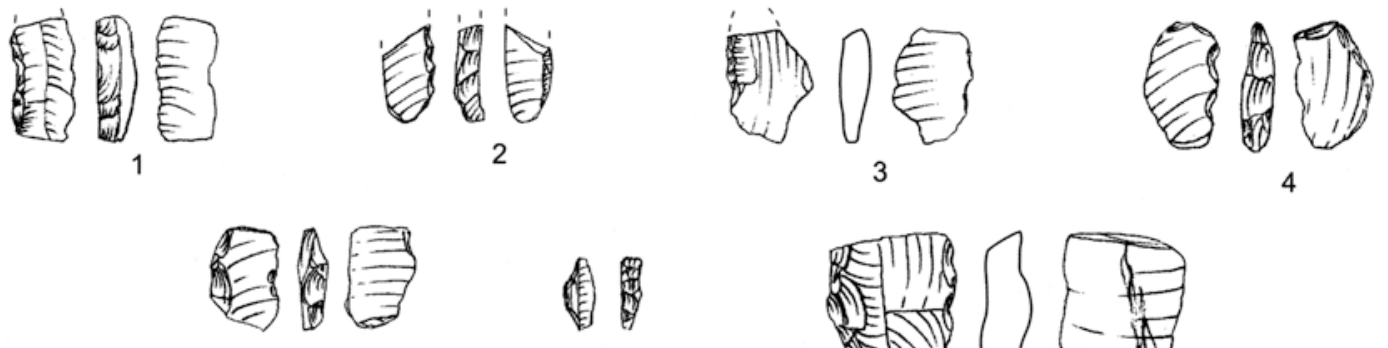

5

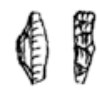

6
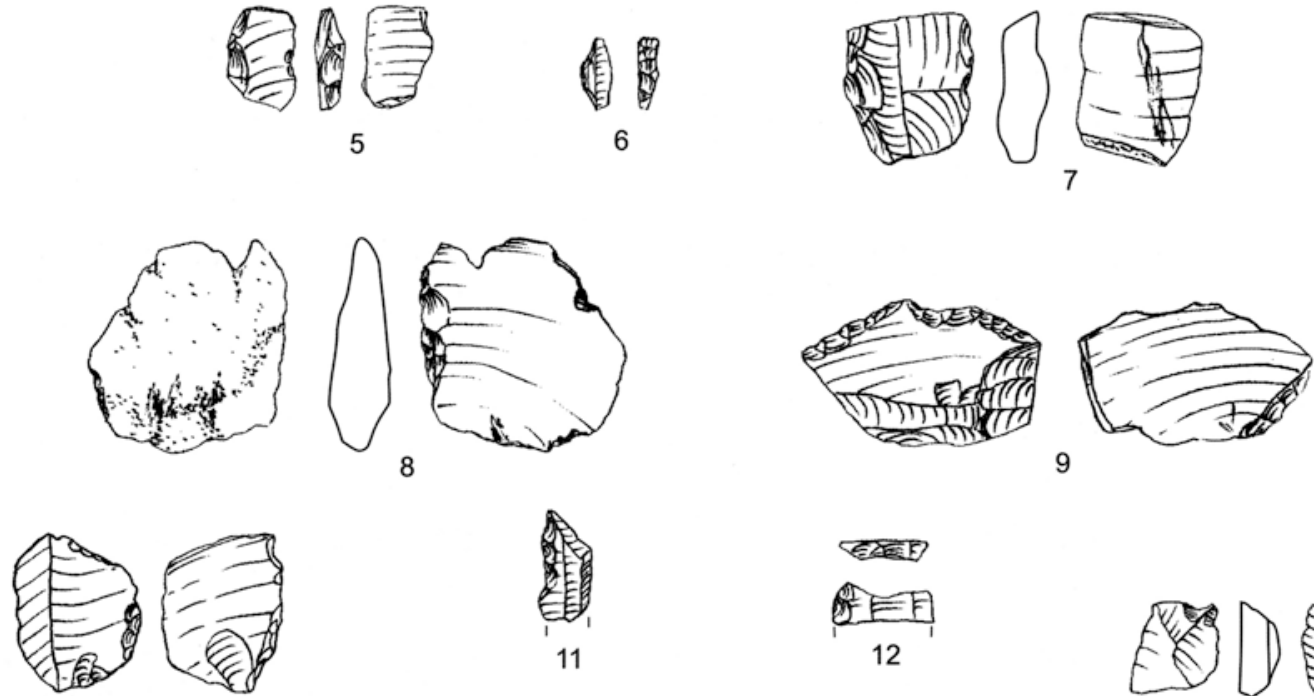

11
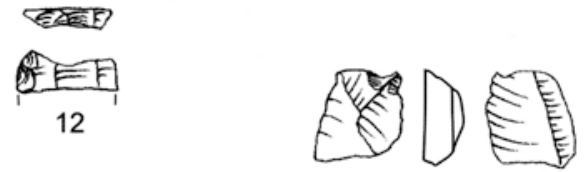

10
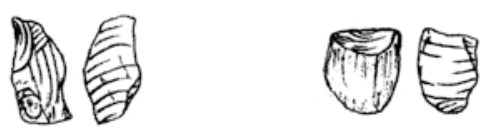

13

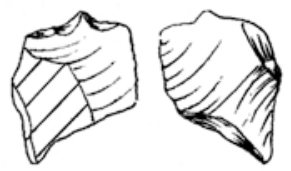

14

15

16

$3 \mathrm{~cm}$

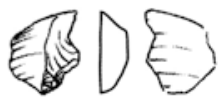

17

Fig. 22.10 Drawings of the chipped stone artefacts recovered from Dive Site C at Aspros. From Kaczanowska and Kozlowski (2014a: Plate II). See Table 22.1 for the description of the respective pieces. Drawings by Janusz Kozłowski

purpose to put the recovery of lithics on a more systematic basis (See Bailey et al. Chap. 3, this volume). Second, there is the need to produce a high definition bathymetry of Dive Site $\mathrm{C}$ and the areas adjacent to it. Third, it would be productive to conduct acoustic seafloor mapping along the foot of the cliff on the north bank of the submerged river valley by using side-scan sonar and multibeam echo sounders. Work of this kind might even lead to the discovery of a submerged rock shelter in the aeolianite cliff. Taking the long view, one would also like to extend the reconnaissance work out to selected places closer to where the shoreline once stood some 12,000 years ago, which will call for more technical dives going down to greater depths in the water.

Our work has demonstrated two important outcomes: first that it is possible to engage in purposeful and successful discovery of underwater sites using a predictive approach based on the location and geomorphology of known archaeological sites on dry land and secondly that it is possible for divers to identify and recover even the smallest types of lithic artefacts from the seabed. Both outcomes hold out the prospect of successful future discoveries of underwater archaeological material. 
Table 22.1 This table lists some of the lithic artefacts recovered at Dive Site C and shown in Figs. 22.9 and 22.10 (after Kaczanowska and Kozlowski 2014a), with details of artefact type and raw material. Numbers in the raw material column refer to different types of flint

\begin{tabular}{|c|c|c|c|c|}
\hline Number & Catalogue number & Artefact type & Raw material & Comments \\
\hline $\mathrm{I}: 1$ & 24 & Core & Flint 7 & \\
\hline $\mathrm{I}: 2$ & 9 & Core fragment & Flint 9 & \\
\hline $\mathrm{I}: 3$ & 11 & Core fragment & Flint 7 & \\
\hline $\mathrm{I}: 4$ & 8 & Fragment of splintered piece & Flint 10 & \\
\hline $\mathrm{I}: 5$ & 21 & Blade fragment & Flint 4 & \\
\hline I:6 & 31 & Flake & Flint 5 & \\
\hline $\mathrm{I}: 7$ & 34 & Flake & Burnt & Top of the cliff \\
\hline $\mathrm{I}: 8$ & 35 & Flake & Patinated & Top of the cliff \\
\hline $\mathrm{I}: 9$ & 25 & Flake & Flint 11 & \\
\hline $\mathrm{I}: 10$ & 10 & Blade fragment & Flint 1 & \\
\hline $\mathrm{I}: 11$ & 2 & Chip & Flint 9 & \\
\hline $\mathrm{I}: 12$ & 3 & Chip & Flint 9 & \\
\hline $\mathrm{I}: 13$ & 1 & Chip & Quartzite & \\
\hline $\mathrm{I}: 14$ & 23 & Blade fragment & Flint 8 & \\
\hline II:1 & 26 & Backed piece & Flint 12 & \\
\hline II: 2 & 50 & Backed piece & Patinated & \\
\hline II:3 & 51 & Backed piece & Flint 8 & \\
\hline II:4 & 20 & Segment & Flint 4 & \\
\hline II:5 & 29 & Segment & Flint 8 & \\
\hline II:6 & 44 & Segment & Flint 1 & \\
\hline II:7 & 33 & Sub-crested retouched blade & Flint 2 & Top of the cliff \\
\hline II:8 & 32 & Retouched flake & Burnt & Top of the cliff \\
\hline II:9 & 6 & Retouched flake & Flint 3 & \\
\hline II:10 & 36 & Retouched flake & Radiolarite 1 & \\
\hline II:11 & 37 & Retouched blade & Patinated & \\
\hline II:12 & 38 & Retouched blade & Flint 5 & \\
\hline II:13 & 19 & $\mathrm{Bec}$ & Flint 7 & \\
\hline II:14 & 7 & Bec on splintered piece & Flint 5 & \\
\hline II: 15 & 30 & Retouched chip & Flint 1 & \\
\hline II:16 & 22 & Retouched chip & Flint 7 & \\
\hline II:17 & 28 & Retouched chip & Flint 2 & \\
\hline
\end{tabular}

The finds were recovered from the base of the underwater cliff except where indicated in the final comments column, where 'top of cliff' refers to the top of the underwater cliff. The numbers in column 1 correspond to the drawings in Figs. 22.9 and 22.10 
Acknowledgements The investigation at Aspros would not have had a positive outcome without the major contributions of the following individuals: Alan Blum; Tim Turnbull, who acted as divemaster; Duncan Howitt-Marshall, who contributed his experience of underwater archaeology; Janusz Kozlowski and Malgorzata Kaczanowska, who undertook the detailed analysis of the lithic artefacts; Pavlos Flourentzos and Jay Noller. Our appreciation goes to INSTAP for the support of the fieldwork on Cyprus.

\section{References}

Ammerman AJ (2010) The first Argonauts: toward the study of the earliest seafaring in the Mediterranean. In: Anderson A, Barret JH, Boyle KV (eds) The global origins and development of seafaring. McDonald Institute for Archaeological Research, Cambridge, pp 81-92

Ammerman AJ (2013) Tracing the steps in the fieldwork at the sites of Aspros and Nissi Beach on Cyprus. In: Ammerman AJ, Davis TW (eds) Island archaeology and the origins of seafaring in the eastern Mediterranean. Proceedings of the Wenner-Gren workshop held at Reggio Calabria on October 19-21, 2012. Part one. Eurasian prehistory, vol 10, pp 117-138

Ammerman AJ (2014a) Aspros and Nissi Beach: tracing the steps in the study of early sites on Cyprus and the origins of seafaring in the Mediterranean world. In: Kaczanowska M, Kozłowski JK, KaminskaSzymczak J (eds) Contributions to the archaeology of early Cyprus. Polish Academy of Arts and Sciences, Krakow, pp 7-26

Ammerman AJ (2014b) Setting our sights on the distant horizon. In: Ammerman AJ, Davis TW (eds) Island archaeology and the origins of seafaring in the eastern Mediterranean. Proceedings of the WennerGren workshop held at Reggio Calabria on October 19-21, 2012. Part two. Eurasian prehistory, vol 11, pp 203-236

Ammerman AJ, Florentzos P, McCartney C, Noller J, Sorabji B (2006) Two new early sites on Cyprus. In: Report of the Department of Antiquities, Cyprus, pp 1-22

Ammerman AJ, Florentzos P, Gabrielli R, McCartney C, Noller J, Peloso D, Sorabji B (2007) More on the new early sites on Cyprus. In: Report of the Department of Antiquities, Cyprus, pp 1-26

Ammerman AJ, Florentzos P, Higham T, McCartney C, Turnbull T (2008) Third report on early sites on
Cyprus. In: Report of the Department of Antiquities, Cyprus, pp 1-32

Ammerman AJ, Howitt Marshall D, Benjamin J, Turnbull $\mathrm{T}$ (2011) Underwater investigations at the early sites of Aspros and Nissi Beach on Cyprus. In: Benjamin J, Bonsall C, Pickard C, Fischer A (eds) Submerged prehistory. Oxbow, Oxford, pp 263-271

Ammermans AJ, Noller JS (2005) New light on Aetokremnos. World Archaeol 37:533-543

Bailey GN (2013) Early seafaring and the archaeology of submerged landscapes. In: Ammerman AJ, Davis TW (eds) Island archaeology and the origins of seafaring in the eastern Mediterranean. Proceedings of the Wenner-Gren workshop held at Reggio Calabria on October 19-21, 2012. Part one. Eurasian prehistory, vol 10, pp 99-114

Balme J, O'Connor S (2014) Early modern humans in island Southeast Asia and Sahul: adaptive and creative societies with simple lithic industries. In: Dennell R, Porr M (eds) Southern Asia, Australia and the search for human origins. Cambridge University Press, Cambridge, pp 164-174

Bar-Yosef O (1998) The Natufian culture in the Levant, threshold to the origins of agriculture. Evol Anthropol Issues News Rev 6(5):59-177

Bar-Yosef Mayer DE, Kahanov Y, Roskin J, Gildo H (2015) Neolithic voyages to Cyprus: wind patterns, routes and mechanisms. J Island Coast Archaeol 10:412-435

Boyd B (2006) On 'sedentism'in the later Epipalaeolithic (Natufian) Levant. World Archaeol 38(2):164-178

Broodbank C (2006) The origins and early development of Mediterranean maritime activity. J Mediterr Archaeol 19(2):199-230

Cherry J (1990) The first colonization of the Mediterranean islands: a review of recent research. J Mediterr Archaeol 3:145-221

Kaczanowska M, Kozlowski J (2014a) Underwater finds from dive site $\mathrm{C}$ at Aspros. In: Kaczanowska M, Kozłowski JK, Kaminska-Szymczak J (eds) Contributions to the archaeology of early Cyprus. Polish Academy of Arts and Sciences, Krakow, pp 59-66

Kaczanowska M, Kozlowski J (2014b) Reconstruction of lithic assemblages from Nissi Beach (Cyprus). In: Kaczanowska M, Kozłowski JK, KaminskaSzymczak J (eds) Contributions to the archaeology of early Cyprus. Polish Academy of Arts and Sciences, Krakow, pp 67-106

Kaczanowska M, Kozlowski J, Kaminska-Szymczak J (2014) Analysis of the artifact collections from 
the littoral zones of Aspros. In: Kaczanowska M, Kozłowski JK, Kaminska-Szymczak J (eds) Contributions to the archaeology of early Cyprus. Polish Academy of Arts and Sciences, Krakow, pp 27-57

Knapp AB (2013) The archaeology of Cyprus: from earliest prehistory through the bronze age. Cambridge University Press, Cambridge

Lambeck K, Rouby H, Purcell A, Sun Y, Sambridge M (2014) Sea level and global ice volumes from the last glacial maximum to the Holocene. Proc Natl Acad Sci 111(43):15296-15303
Simmons AH (1999) Faunal extinction in an island society: pygmy hippopotamus hunters of Cyprus. Kluwer, New York

Yalçinkaya I, Otte M, Kozlowski JK, Bar-Yosef O (2002) La grotte d' Öküzini: Évolution du Paléolithique final du sudouest de l'Anatolie. Études et Recherches Archéologiques de l'Université de Liège 96. Liège, Belgium

Zazzo A, Lebon M, Quiles A, Reiche I, Vigne JD (2015) Direct dating and physico-chemical analyses cast doubts on the coexistence of humans and dwarf hippos in Cyprus. PLoS One 10(8):e0134429. https://doi. org/10.1371/journal.pone.0134429

Open Access This chapter is licensed under the terms of the Creative Commons Attribution 4.0 International License (http://creativecommons.org/licenses/by/4.0/), which permits use, sharing, adaptation, distribution and reproduction in any medium or format, as long as you give appropriate credit to the original author(s) and the source, provide a link to the Creative Commons licence and indicate if changes were made.

The images or other third party material in this chapter are included in the chapter's Creative Commons licence, unless indicated otherwise in a credit line to the material. If material is not included in the chapter's Creative Commons licence and your intended use is not permitted by statutory regulation or exceeds the permitted use, you will need to obtain permission directly from the copyright holder. 